\title{
Erratum to: Validation of specificity of antibodies for immunohistochemistry: the case of ROR2
}

\author{
Sean S. Q. Ma ${ }^{1} \cdot$ Claire E. Henry $^{1} \cdot$ Estelle Llamosas $^{1} \cdot$ Rupert Higgins $^{1} \cdot$ \\ Benjamin Daniels $^{2} \cdot$ Luke B. Hesson $^{3} \cdot$ Nicholas J. Hawkins $^{4} \cdot$ Robyn L. Ward ${ }^{4}$. \\ Caroline E. Ford ${ }^{1}$
}

Received: 7 July 2016 /Revised: 7 August 2016 / Accepted: 1 September 2016 / Published online: 29 October 2016

(C) Springer-Verlag Berlin Heidelberg 2016

\section{Erratum to: Virchows Arch}

\section{DOI 10.1007/s00428-016-2019-5}

Due to a typographical error, Abcam antibody ab92379 was incorrectly listed as a mouse antibody when it is in fact a rabbit antibody. The authors apologize for not noticing this error in the proofs.
The sentence in the "Methods" section should read as follows: Individual membranes were then incubated with the antiROR2 antibodies: rabbit monoclonal (ab92379, Abcam), rabbit polyclonal (HPA021868, Sigma-Aldrich), and mouse monoclonal (QED Bioscience), respectively, at 1:1000 dilution in $3 \%$ milk in TBS-Tween at 4OC overnight. The entries in Table 1 should read as follows:

\begin{tabular}{|c|c|c|c|c|c|c|c|}
\hline Product name & Clonality & Origin and specificity & Usage & Predicted size & Supplier & Catalogue no. & References \\
\hline Anti-ROR2 antibody ${ }^{\mathrm{a}}$ & Monoclonal & Rabbit anti-human & Flow, ICC, WB & $105 \mathrm{kDa}$ & Abcam & ab92379 & {$[17,31]$} \\
\hline
\end{tabular}

The online version of the original article can be found at $\mathrm{http}: / \mathrm{dx}$. org/10.1007/s00428-016-2019-5

Caroline E. Ford

caroline.ford@unsw.edu.au

1 Adult Cancer Program, Level 2, Metastasis Research Group, Lowy Cancer Research Centre and School of Women's and Children's Health, University of New South Wales, Sydney, NSW 2052, Australia

2 Faculty of Medicine, Medicines Policy Research Unit, Centre for Big Data Research in Health, UNSW, Sydney, Australia

3 Colorectal Cancer Group, Adult Cancer Program, Lowy Cancer Research Centre, UNSW, Sydney, Australia

4 University of Queensland, St. Lucia, Australia 